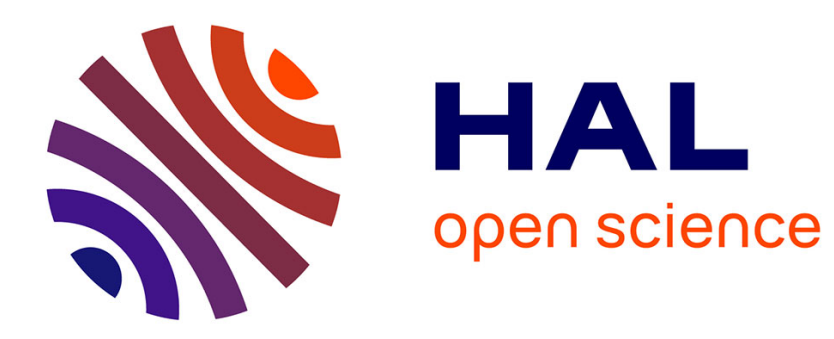

\title{
Experimental assessment of dry stone retaining wall stability on a rigid foundation
}

\author{
B. Villemus, J.C. Morel, C. Boutin
}

\section{To cite this version:}

B. Villemus, J.C. Morel, C. Boutin. Experimental assessment of dry stone retaining wall stability on a rigid foundation. Engineering Structures, 2007, 29 (9), pp.2124-2132. hal-00941189

\section{HAL Id: hal-00941189 \\ https://hal.science/hal-00941189}

Submitted on 3 Feb 2014

HAL is a multi-disciplinary open access archive for the deposit and dissemination of scientific research documents, whether they are published or not. The documents may come from teaching and research institutions in France or abroad, or from public or private research centers.
L'archive ouverte pluridisciplinaire HAL, est destinée au dépôt et à la diffusion de documents scientifiques de niveau recherche, publiés ou non, émanant des établissements d'enseignement et de recherche français ou étrangers, des laboratoires publics ou privés. 


\title{
Experimental assessment of dry stone retaining wall stability on a rigid foundation
}

\author{
B. Villemus, J.C. Morel*, C. Boutin \\ Département Génie Civil et bâtiment (CNRS, URA 1652), Ecole Nationale des Travaux Publics de l'Etat, rue M. Audin, 69518 Vaulx-en-Velin cedex, France
}

\begin{abstract}
Dry stone masonry retaining walls are present in the majority of mountainous areas all around the world, but the technique is marginal today in developed countries. The emergence of the concept of sustainable development calls for renewed use of this technique, both for the repair of existing retaining walls and the building of new ones. The objective of this research was to seek the knowledge necessary to ensure the stability of these structures, using experimental investigations in the laboratory and in situ. From this work, a model has been developed for calculating the stability of dry stone retaining walls. After laboratory testing to quantify the interface friction, the data obtained were used in a model based on the equilibrium of the forces at failure. The model considers the possibility of the internal failure of the wall, taking into account the irregularity of the geometry of the stones and of their arrangement, using a parameter determined by in situ experiments. Full-size on-site experiments on 5 walls ( 2 and $4 \mathrm{~m}$ high), loaded using hydrostatic pressure, are presented. These allowed quantification of the parameters of the model, and its validation for two types of material. These tests also determined the limits of monolithic behaviour of the masonry, thus defining failure and enabling the fulfilment of practical engineering requirements.
\end{abstract}

Keywords: Dry stone masonry retaining walls

\section{Introduction}

Dry stone masonry is a vernacular construction method found in various forms, in many areas all around the world. The system of construction consists in the laying out of the stones without using mortar, and calls for skilled masons. They must be able to make decisions about which stone to use and where to place it, while complying with the essential rules of dry stone masonry. The walls were generally built using materials directly available on or close to the site, which explains the great diversity of the existing works and their integration into the landscape. These walls often sat on the rock substratum, as the presence of stones on the surface, used in the construction, results from the rock existing at shallow depth.

Dry stone walling in European countries is considered to contribute to landscapes and cultures, and to make an important economic contribution to existing craft, agriculture and tourism

\footnotetext{
* Corresponding author.

E-mail address: morel@entpe.fr (J.C. Morel).
}

industries. Considering sustainable development objectives, dry stone has many advantages, especially if the stones are obtained from local quarries or are found in situ [10]. It thus seems legitimate to rehabilitate this ancestral technique, but this requires the establishment of scientific knowledge of the specific behaviour of dry stone retaining walls.

There is good historical literature relating to dry stone [2, 6], describing primarily, based on the empirical understanding of the relevant time, empirical methods for determining the dimensions of these walls. However, these are not usable for deriving modern engineering standards.

The principal difference between dry stone retaining walls and those constructed from concrete, or mortared masonry, is the absence of cohesion between the stones, which allows internal deformation. Moreover, the layering of the stone introduces sliding planes, which may open. It is proposed that these points should be accounted for in determining dimensions.

The modelling of a dry stone wall is difficult, because behind the apparent regularity of an existing wall face, many variations are hidden. These relate to the use of the natural materials 
available at the local level, and result in some heterogeneity of the geometry, arrangement and even strengths of the various stones of the wall, which are not taken into account by existing theoretical approaches:

- The model based on periodic homogenisation of masonry [5] as a regular block stack cannot take the stone variability or movement into account.

- The Discrete Element Method (DEM) used to model dry stone masonry by Dickens [8], Harkness [9] and Claxton [4] gives remarkable results for large displacements, but knowledge of stiffness parameters is required. These parameters are difficult to determine by experiment, particularly because of the strong heterogeneity of the walls. Modelling the real geometry of all blocks requires considerable work.

- the FEM used by Zhang et al. [12] has similar problems to DEM.

An alternative approach was therefore preferred, with a simpler model based on experimental observations, one more easily adopted in engineering practice. Experimental tests were conducted to characterize the constitutive elements of the wall (the stones, and the interfaces between them), and then the masonry itself, using hydrostatic loading of full scale walls.

This article is structured in three parts. The first part presents the experiments carried out in the laboratory on components of the wall: interface shear tests between two individual stones, and between two beds of stone.

The second part describes the proposed theoretical model, which considers the stability of the wall as a homogeneous structure on a rigid foundation. Its originality comes from the fact that it takes account of the characteristics of the material - the irregularity of the geometry of the stones and their arrangement - using the parameter $\Theta$, measured on site, which is the slope of the internal shear band compared to the initial stone bed. It is shown that it is necessary to take into account this internal failure, because it leads to the instability of the structure.

The third part presents the experimental in situ loading test of five walls by hydrostatic pressure. These tests were carried out on dry stone walls of 2 and $4 \mathrm{~m}$ height, built by skilled masons, in conformity with current and traditional best practice. They made it possible to quantify and validate the parameters of the model for two types of stone: limestone and schist.

Close attention was paid to displacement measurement analysis during the experiments, because the model cannot give information on displacements. The use of stereophotogrammetry [7] on the end elevation of a length of wall allows determination of local displacements on an entire section of wall, thus checking the two-dimensional displacement behaviour. This information was compared with observations using sensors on the front elevation, and with the direct measurement of the parameter $\Theta$.

\section{Mechanical behaviour of "dry stone" material}

The integrity of a dry stone wall is related to the stones which make it up. But Villemus [11] showed that the compression

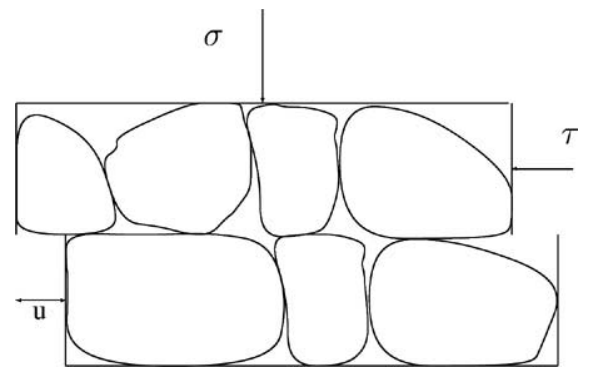

Fig. 1. Two stone beds inside the LIRIGM shear box $100 \mathrm{~cm} \times 100 \mathrm{~cm}$.

strength of stone within a wall height lower than $6 \mathrm{~m}$, which represents approximately $90 \%$ of existing walls in France on the national road network, seems sufficient. On the other hand, in the case of soft foundations, the compressive strength of the soil is critical in determining the dimensions of the wall.

\subsection{Interface behaviour measured by the shear test}

The shear strength of dry stone beds must be high enough to limit the displacement of the stone, in order to guarantee monolithic behavior of the wall. As a first investigation, the interface behavior between two cut stones was measured on samples $6 \mathrm{~cm} \times 6 \mathrm{~cm}$ and $30 \mathrm{~cm} \times 30 \mathrm{~cm}$, using a shear box $30 \mathrm{~cm} \times 30 \mathrm{~cm}$ at the LIRIGM of Grenoble and a traditional $6 \mathrm{~cm} \times 6 \mathrm{~cm}$, direct shear box. The cut sample faces removed the problem of macrorugosity.

However, to measure in a more realistic way what occurs in situ, shear tests were also carried out using a very large shear box, allowing the effect of interactions between the stones due to a wall's vertical and horizontal joints to be taken into account. In addition, this made it possible to represent correctly the macrorugosity of the various stones. The prototype shear box of $100 \times 100 \mathrm{~cm}^{2}$ [1] at LIRIGM of the Grenoble J. Fourier University was used. This allowed dry stone to be made in the lower box, to be sheared by a second bed, assembled in the upper box, Fig. 1.

For the filling of the lower half-box, the stones were selected so as to ensure a relatively flat upper surface of the stone bed, lying as close as possible to the shear plane of the box. Once arranged, the stones were wedged in place using small stones.

During the filling of the upper half-box, the vertical joints were crossed carefully to avoid continuous vertical joints across the shear plane. Wooden wedges and stiff barbed polymer geomembranes were placed between the stones and the horizontal plate of the shear box to ensure that all the stones had at least one contact with the plate transmitting the vertical load.

The vertical load produced an average normal stress varying from 30 to $130 \mathrm{kPa}$, roughly equivalent to the base of a wall $7.5 \mathrm{~m}$ high at the upper end. The shear rate was not constant, but was kept below $3 \mathrm{~mm} / \mathrm{min}$. The test was carried out on the same sample four times, with increasing values of normal stress. The displacement response from this procedure may not be equivalent to the real shear displacement, but this does not have serious implications on the calculation of the parameters $c_{m}$ and the $\varphi$ of the Coulomb law. 


\begin{tabular}{llll}
\hline Stone name & $\begin{array}{l}6 \times 6 \mathrm{~cm}^{2} \text { box, } \\
\text { cut samples }\end{array}$ & $\begin{array}{l}30 \times 30 \mathrm{~cm}^{2} \text { box, } \\
\text { cut samples }\end{array}$ & $\begin{array}{l}100 \times 100 \mathrm{~cm}^{2} \text { box, } \\
\text { uncut samples }\end{array}$ \\
\hline $\begin{array}{l}\text { Limestone from fields } \\
\text { Limestone of "St Gens" }\end{array}$ & $37 \pm 2^{\circ}$ & $37 \pm 1^{\circ}$ & $38 \pm 2^{\circ}$ \\
Not measured & $36 \pm 1^{\circ}$ & N \\
\hline
\end{tabular}

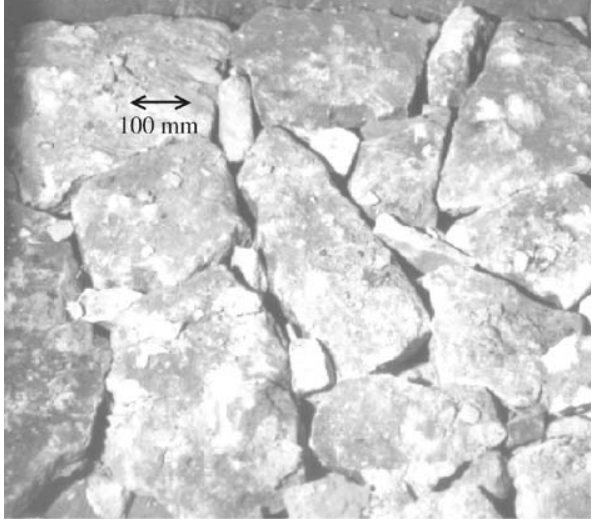

Fig. 2. Lower stone bed after shear testing of two stone beds $100 \mathrm{~cm} \times 100 \mathrm{~cm}$ (limestone). The white zone consists of crushed pieces of stone.

During the test, stones sometimes broke by flexure, especially under high loadings. The surface of the stones was abraded, especially by sand created by crushing of the stone, as shown in Fig. 2.

Cohesion is always neglected, since it is induced by the very large shear box. The angle of friction obtained is close to that found by the other shear boxes, Table 1. It is extraordinary that the test with the small shear box makes it possible to directly obtain the friction at the interface between two stone beds. Following this finding, the angle of friction of the schists of "St Germain de Calberte" used in Section 4 was only measured by the $6 \times 6 \mathrm{~cm}^{2}$ shear box.

\section{Limit equilibrium analysis of a dry stone masonry retaining wall}

Dry stone retaining walls are load bearing retaining walls, which have long been analysed by considering the equilibrium of forces and moments applied to the wall treated as a rigid solid. This assumption is checked by determining if the resultant force lies within the central third of the foundation. In current engineering, external forces are usually obtained using the earth pressure coefficients given by Caquot et al. [3]. However, the test walls described here were loaded by water, giving simple hydrostatic pressure $\overrightarrow{p_{w}}$, with no shear component on the back of the wall, see Fig. 3.

A priori, a dry stone wall cannot be regarded as a rigid solid, even if the middle third rule is satisfied at the level of each stone bed, so that the wall is carrying the vertical compression throughout. A potential internal shear failure within the masonry AO (see Fig. 3) is defined by the angle $\theta$ and the height $h_{o}$ where it emerges at the wall face, Fig. 3.

\subsection{Wall behaviour assumptions}

The following assumptions are made regarding the behaviour of the wall:

- There is no interaction between failure by the sliding/shearing of joints, and failure by rotation.

- The friction mobilised in shearing in the joints in the wall is given by the stone-stone friction measured in the laboratory, and corresponds to a pure Coulomb type of angle of friction $\varphi_{m}$, see Section 2.

- The inclination of the failure plane for shearing on the dry joints is given by an angle $\theta$ to horizontal, which may differ from the orientation of the construction bedding planes at an angle $\eta$ to the horizontal. The inclination of the failure plane relative to the bedding planes is given by $\Theta$, Fig. 3 . This is because the irregularity of the stones allows rotation, crushing or displacement as the load is applied.

The two parameters, angle $\theta$ and height $h_{o}$, are thus characteristics of the wall construction, geometry and loading. They must be measured by experiment. The height $h_{o}$ is a priori null if the foundation is a soft soil. The first stone bed will punch the soil, allowing rotation to the angle $\theta$. In the case of the experimental walls, the foundation was rigid and one to two joints were necessary to enable rotation. We are assuming $h_{o}=0$ gives larger loads, and so errs in the direction of safety.

\subsection{Internal stability}

If a linear stress distribution is assumed within the stone beds, the sections of the wall always remain compressed when the resultant force stays inside the central third of the wall section, which limits the relative eccentricity to $k=\frac{1}{6}$. As the dry stone construction has no tensile strength in the joints, if the resultant lies in front of the middle third, then there is no compression at the back of the wall, and the linear stress distribution starts from zero at a point which moves closer to the wall face as the eccentricity increases. Considering the moment equilibrium about the front of the wall gives a limiting value $k=\frac{1}{2}$. Between $\frac{1}{6}$ and $\frac{1}{2}$ the wall is still potentially stable, but as the value approaches $\frac{1}{2}$, the vertical stresses increase rapidly, reaching infinity at $k=\frac{1}{2}$. The simple assumption of linear stress distribution would, of course, be incorrect well before this stage is reached, if it is ever even approximately correct in a dry stone wall, which tends to deform primarily in shear rather than in the pure bending which is implicit in the assumption of a linear stress distribution.

In order to evaluate internal shear stability, the equilibrium of the forces is examined, Fig. 3. There is stability when 


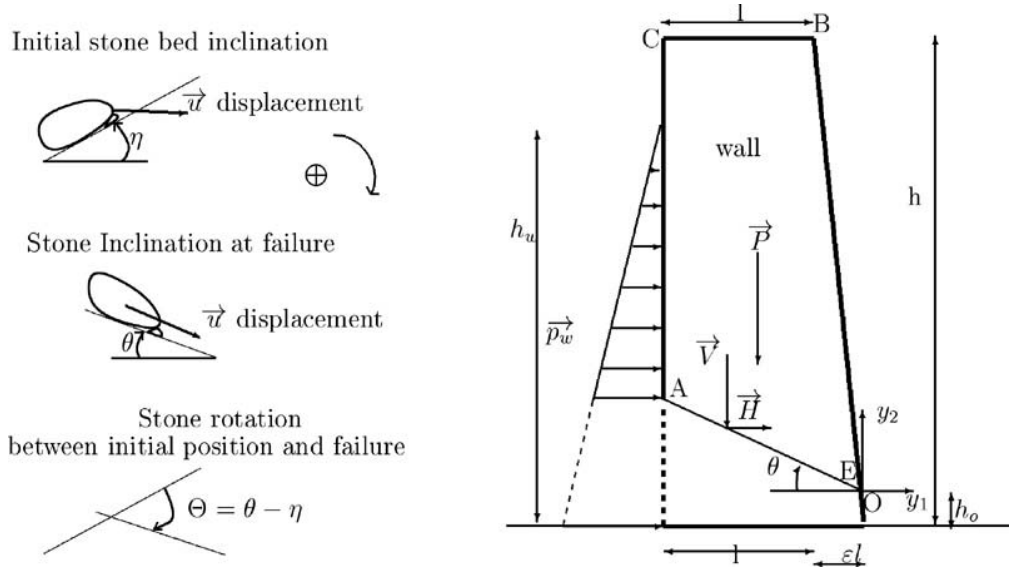

Fig. 3. Geometry at failure, $\eta$ initial inclination of stone beds.
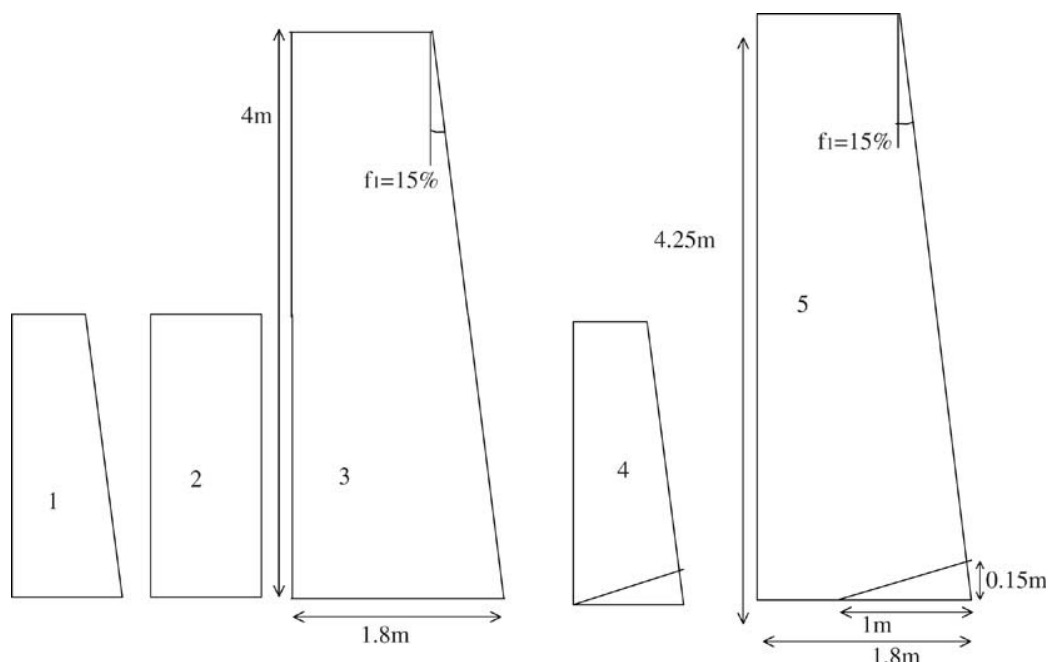

Fig. 4. Tested wall geometry. The hydrostatic load is applied on the left side.

the interface friction angle $\varphi_{m}$ is high enough to allow the horizontal forces to be resisted. This is quantified by the safety coefficient $F_{g}$ :

$F_{g}=\frac{V \tan \left(\varphi_{m}-\theta\right)}{H}$

with $V$ and $H$ being the resultant forces from the external forces applied to solid OACB.

Though very simple, the calculation cannot be carried out without full-scale experiments to give the values of $\theta$ and $h_{o}$, and to validate the method of calculation.

\section{Loading test on full scale dry stone retaining walls}

Five walls were constructed for this study, with varying geometries as shown in Fig. 4, with maximum heights up to $4 \mathrm{~m}$ (walls 3 and 5). The use of rough stones from local quarries, St Gens limestone for walls 1-4, and schist from St Germain de Calberte (France) for the fifth, conforms to local practice for construction of such walls. The use of schist for wall 5, a denser stone with lower friction, in thinner pieces, makes it possible to test the reproducibility of the model on a another type of stone.

\subsection{Experimental device}

The five walls were built by skilled dry stone masons (see acknowledgement). In Fig. 5 the particular heterogeneity of the geometry of the stones and the relatively regular stone beds can be seen. The presence of a batter (walls 1, 3, 4, 5 ) is in conformity with the majority of existing walls, and helps prevent overturning failure. Moreover, the batter makes the construction process slightly easier if the stone beds are perpendicular to the wall face (walls 4 and 5). The initial slope of the stone beds increases the internal shear strength of the wall.

Instead of using earth pressure to load the walls, hydrostatic pressure (in the form of water in a large PVC-lined bag) was applied. With no friction on the back of the structure, and a loading more precisely predictable than would be obtained from a compacted fill, this allowed the study to focus on the internal shear strength of dry stone masonry. These tests as a result do not make it possible to study the interaction between the wall and the embankment, but the effect of this can be estimated elsewhere using conventional practice, starting from the knowledge already established for the retaining walls, [3]. 

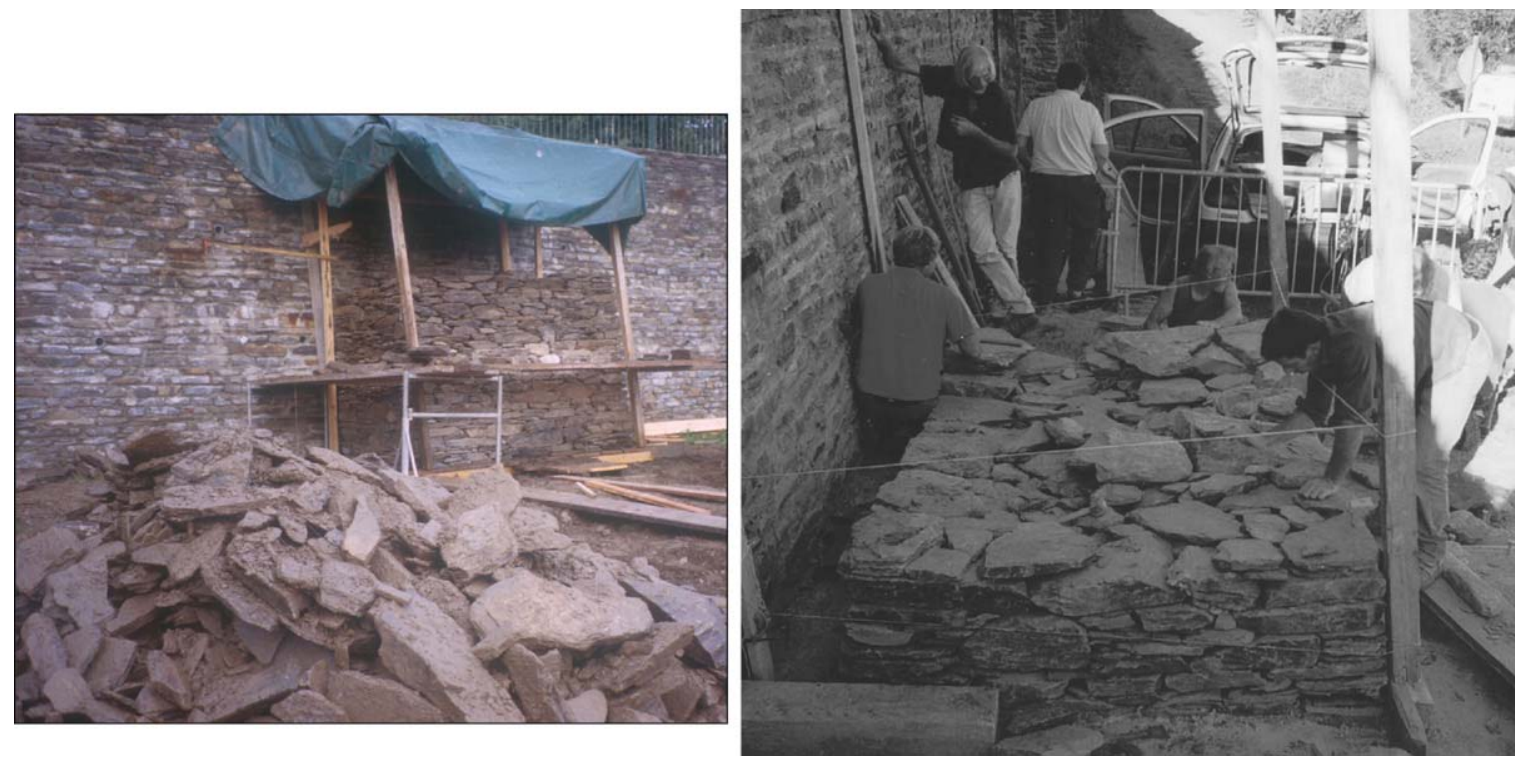

Fig. 5. Wall 5 construction; left: stone size heterogeneity, right: wall basement construction.

Table 2

Geometric and mechanical data about tested walls

\begin{tabular}{|c|c|c|c|c|c|}
\hline & Wall 1 & Wall 2 & Wall 3 & Wall 4 & Wall 5 \\
\hline Height $h+h_{o}(\mathrm{~m})$ & 2 & 2 & 4 & 2 & 4.25 \\
\hline Free height unblocked at the basement (m) & 1.85 & 1.85 & 3.85 & 1.90 & 4.10 \\
\hline Top width (m) & 0.6 & 0.9 & 1.2 & 0.65 & 1.16 \\
\hline Basement width (m) & 0.9 & 0.9 & 1.8 & 0.9 & 1.8 \\
\hline Batter f1 (\%) & 15 & 0 & 15 & 12 & 15 \\
\hline$\varepsilon$ & 0.5 & 0 & 0.5 & 0.38 & 0.5 \\
\hline Volumic weight $\left(\mathrm{kN} / \mathrm{m}^{3}\right)$ & 15.4 & 15.0 & 15.7 & 16.0 & 18.0 \\
\hline Void percentage & 25 & 27 & 24 & 23 & 32 \\
\hline Stone friction angle (in degree) & 36 limestone & 36 limestone & 36 limestone & 36 limestone & 28.5 schist \\
\hline Inclination of stone bed & Horizontal & Horizontal & Horizontal & $\eta=4^{\circ}$ & $\eta=8.5^{\circ}$ \\
\hline
\end{tabular}

Each wall was weighed after testing, so that together with measurements of the volume of the wall, the masonry's unit weight could be obtained, Table 2. For example, wall 3 was built with twenty-nine tons of stone.

\subsection{Displacements measurement}

From 8 to 10 displacement sensors measured the movement of the central section of the face of each wall during the loading. To supplement these measurements, photographic slides of one side of the wall were taken from a fixed point. The stereophotogrammetric analysis of these slides enabled the displacement of each stone to be determined, allowing the:

- comparison of the movement of the central part of the face measured by the sensors with the movements on one end of the wall at the same time, and hence validation of the assumption of plane strain.

- determination of the kinematics of failure, by observing the slip lines as well as the overall rotation.

The particular use of stereophotogrammetry in this project involves the photographic recording of two images of the same plane object undergoing a plane strain. The two images are photographed from the same place, but at two different times. Slides measuring $6 \mathrm{~cm}$ by $6 \mathrm{~cm}$ were used. When viewed with a stereoscope, a false relief appears where there has been displacement within the plane between the two images. This false relief is proportional to the displacements which have occurred, and can be observed and recorded using normal stereographic procedures. This work was done in Laboratory $3 \mathrm{~S}$ of Grenoble (data stereo-scope and processing). Further details of the technique are given by Desrues [7].

The displacements determined have an accuracy limited by the scale factor. The measurements on the images allowed an accuracy of $+/-0.005 \mathrm{~mm}$. Wall 3 , which was $4 \mathrm{~m}$ high, was represented by $51 \mathrm{~mm}$ on the slide, giving a scale factor of 78.4. The resulting accuracy of displacement measurement was $+/-0.4 \mathrm{~mm}$, similar to that of the cable sensors.

The strain field was obtained using the Anadef software developed by Desrues [7]. From the points measured by a stereoscope, this software carries out a triangulation of the measured displacement field, the material being regarded as continuous, and hence mapping the strain tensor. The fourmetre high walls comprised about 30 stone beds, each bed including 6-10 stones from the front to the back of the wall. The simplification of continuity for the purposes of stereographic 

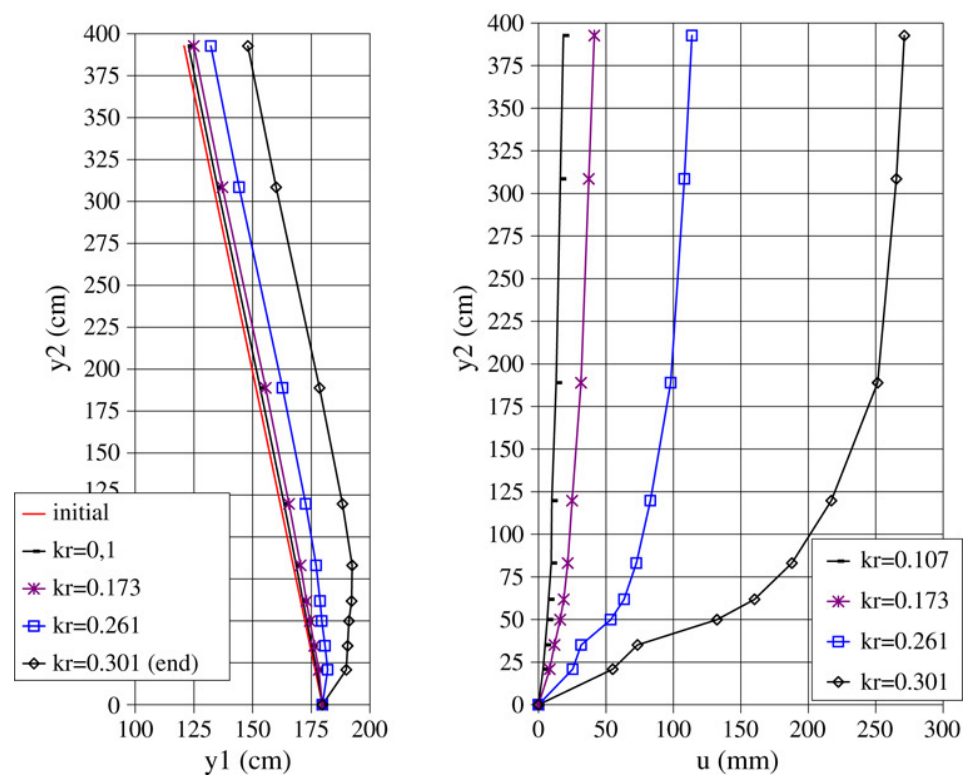

Fig. 6. Wall 5, left: wall facing displacement for varying relative eccentricity $k$; right: horizontal displacement $u$ versus stone position $y_{2}$ with a dilated scale.

mapping of displacements was thus found to be acceptable for qualitative interpretations.

\subsection{Wall 5 loading test analysis}

Only the results of wall 5 are presented in detail here. The full results are given in Villemus [11]. The model presented in Section 3 gives the following requirements for stability of the walls:

- $k$ for overturning: marginal stability in the range $|k|<\frac{1}{2}$, certain stability for $|k|<\frac{1}{6}$,

- $F_{g}$ for translation: stability for $F_{g}>1$.

\subsubsection{Displacements of the front face}

The study of the movement of the front face of wall 5 (Fig. 6) showed the following characteristics, which had also been shown by the other walls:

- As the load increased, the wall remained a monolith until a load corresponding to $k=1 / 6\left(F_{g}>1.2\right)$. Beyond this load, the internal displacements were high but the wall remained stable.

- The wall is sheared from the base, the shear band increasing with the loading.

The Fig. 7 shows the wall before and after the failure. The belly-shaped deformation may be seen from both ends of the wall. Even after high displacements, the wall remained stable thanks to internal reorientation of the masonry, which is characteristic of the material.

Fig. 8(a) shows the relationship between displacements of points of the facing obtained from the cable sensors at the middle of the wall and the height of the water applying pressure to the back of the wall. These curves are of the same type as those obtained by direct shear testing of the stone interface. Full frictional strength was mobilised with displacements of just a few $\mathrm{mm}$.

\subsubsection{Comparison with stereophotogrammetric data}

Stereophotogrammetric measurements were obtained for the entire cross section of the wall on the end elevation, whereas the cable sensors relate to the median of the external face of the wall. It is thus useful to check if the movement of the wall was uniform along its length, so that the measurements obtained by the two methods were the same. In Fig. 8(b), for the slide pair 01-03, the results obtained by the two methods are seen to be close together. The levels of loading corresponding to the slides are shown in Fig. 8(a). This indicates that the hypothesis of plane behaviour was correct.

The maps of the displacement vectors from slide pairs 01-04 are given in Fig. 9(a). The end section of wall photographed was not visible entirely, because the formwork retaining the PVC liner containing the water hid $30 \mathrm{~cm}$ of the back of the wall. The contours of displacement measured by stereophotogrammetric analysis therefore do not cover the entire cross-section of the wall. Nevertheless, a good representation is given of internal displacements of the wall, since the visible part corresponds to $80 \%$ of the total surface of the section. For clarity, the displacement vectors are drawn to an exaggerated scale. The measured area after deformation is represented on Fig. 9(a) by the dotted line.

The displacement vectors of (Fig. 9(a)) highlight the kinematic nature of the failure, which is an overall horizontal slip (pair 02-03 and 03-04). There is a rearrangement of the stones at a downward angle of approximately $11^{\circ}$ (pair 01-02); for the following pairs, the slip tended to be approximately horizontal on the first "free" dry stone bed (located above the bed blocked by the foundation), and very slightly tilted $\left(2.5^{\circ}\right.$ downwards) for the second "free" bed.

The failure of wall 5 was localized at the base of the wall; the remainder of the wall had a behavior under loading which was close to a rigid behavior, Fig. 9 . 
J.B. Lanaspèze), the quarry "Mallet", the "Parc National des Cevennes", the FFB, "Chambre de métier de Lozère", "Maisons Paysannes de France", "commune de St Germain de Calberte". We thank also J.P. Gourc, H. Mora, P. Goteland and Y. Orengo from the LIRIGM for the use of the large shear boxes, and finally J. Desrues (Laboratory 3S) for allowing us to use the stereophotogrammetry device, and C. Rousseau for assistance in its use.

\section{References}

[1] Aboura A. Etude expérimentale et mise au point d'une boîte de cisaillement pour caractériser les déchets ménagers, thèse de l'UJF. 1999. p. 193.

[2] Burgoyne J. Revetments or retaining walls. Corps of Royal Engineering Papers 1853;3:154-9.

[3] Caquot A, Kerisel J, Absi E. Tables de butée et de poussée. Paris: G. Villars; 1948.

[4] Claxton M, Hart RA, McCombie PF, Walker PJ. Rigid block distinct element modeling of dry stone retaining walls in plane strain. Journal of
Geotechnical and Geoenvironmental Engineering 2005;381-9.

[5] De Buhan P, De Felice G. A homogenization approach to the ultimate strength of brick masonry. Journal of the Mechanics and Physics of Solids 1997;45(7):1085-104.

[6] Delaître M. Manuel de l'architecte et de l'ingénieur. Paris. 1825.

[7] Desrues J, Duthilleul B. Mesure du champ de déformation d'un objet plan par la méthode stéréophotogrammétrique de faux relief. Journal de mécanique théorique et appliquée 1984;3(1):79-103.

[8] Dickens JG, Walker PJ. Use of distinct element model to simulate behaviour of dry stone walls. Structural Engineering Review 1996;8: 187-99.

[9] Harkness RM, Powrie W, Zhang X, Brady KC, O’Reilly MP. Numerical modelling of full-scale tests on drystone masonry retaining walls. Géotechnique 2000;50(2):165-79.

[10] Morel JC, Mesbah A, Oggero M, Walker P. Building houses with local materials: Means to drastically reduce the environmental impact of construction. Building and Environment 2001;36:1119-26.

[11] Villemus B. Etude des murs de soutènement en maçonnerie de pierres sèches. Thèse de doctorat de l'INSA-ENTPE. 2004. p. 247.

[12] Zhang X, Koutsabeloulis NC, Hope S, Pearce A. A finite element analysis for the stability of dry stone masonry retaining walls. Géotechnique 2004; 54(1):57-60. 